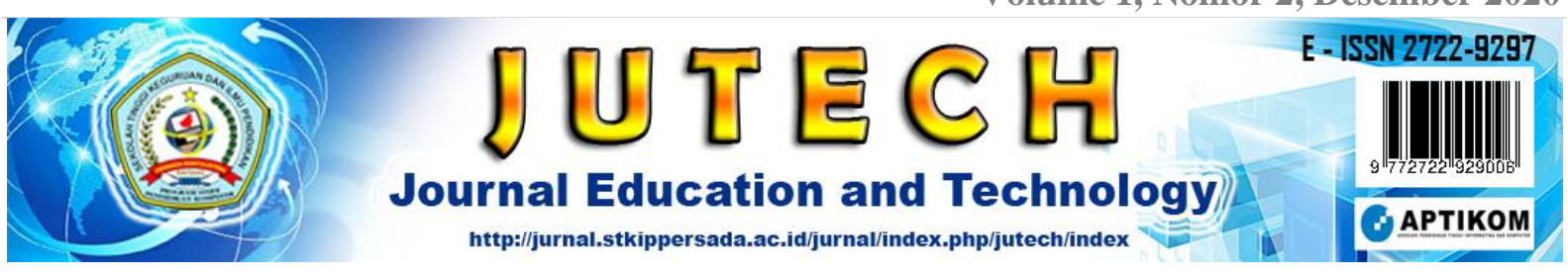

\title{
IMPLEMENTASI MODEL REGRESI LINEAR SEDERHANA UNTUK PREDIKSI GAJI BERDASARKAN PENGALAMAN LAMA BEKERJA
}

\author{
Yayan Adrianova Eka Tuah ${ }^{1}$, Anyan ${ }^{2}$ \\ ${ }^{1,2}$ Program Studi Pendidikan Komputer, STKIP Persada Khatulistiwa Sintang \\ Email:yayan.adrianova.eka.tuah89@gmail.com ${ }^{1}$,anyanright@gmail.com ${ }^{2}$
}

\section{Informasi Artikel}

Riwayat artikel :

Disubmit : 27 Nopember 2020

Direvisi : 11 Desember 2020

Diterima : 28 Desember 2020

Dipublikasi : 30 Desember 2020

\section{Keywords:}

Salary, Work experience, Performance, Linear

Regression

\section{ABSTRACT}

The company cannot be separated from the workforce. Even though the company has advanced technology and large capital. One of the important factors to boost the performance of the workforce is the provision of appropriate salaries based on the length of time they work. This study aims to determine the prediction of employee salaries based on years of service. In this study, the factors that were tested included independent variables in the form of salary and years of service. Then the dependent variable is employee performance. This type of research is ex-post facto research to find out events that have occurred in the company as predictors of employee performance. Methods of data collection using a questionnaire (questionnaire). Instrument validation uses expert opinion and productmoment correlation. The data analysis technique uses linear regression analysis in python machine learning to determine the effect of the independent variable on the dependent variable. The results obtained from this study are a positive and significant influence between salary and years of service on employee performance. The conclusion that can be drawn is that the independent variable can be used as a predictor of the dependent variable. This means that the greater the salary and the longer the working period, the better the employee's performance will be.

\section{ABSTRAK}

Kata Kunci:

Gaji, Pengalaman Bekerja, Kinerja, Regresi Linear
Perusahaan tidak dapat dipisahkan dengan tenaga kerja. Sekalipun perusahaan mempunyai teknologi canggih dan modal besar. Salah satu faktor penting untuk mendongkrak kinerja tenaga kerja adalah pemberian gaji yang sesuai berdasarkan lama waktu mereka bekerja. Penelitian ini bertujuan untuk mengetahui prediksi gaji karyawan berdasarkan tahun lama masa kerja. Dalam penelitian ini, faktor-faktor yang dilakukan pengujian di antaranya variabel independen berupa gaji dan masa kerja. Kemudian variabel dependen beupa kinerja karyawan. Jenis penelitian ini adalah penelitian ex-post facto untuk mengetahui peristiwa yang sudah terjadi dalam perusahaan sebagai prediktor kinerja karyawan. Metode pengumpulan data menggunakan metode angket (kuesioner). Validasi instrumen menggunakan pendapat ahli dan korelasi product moment. Teknik analisis data menggunakan analisis regresi linear dalam python machine learning untuk pengetahui pengaruh variable bebas terhadap variable terikat. Hasil yang didapatkan dari penelitian ini adalah adanya pengaruh positif dan signifikan antara gaji dan masa kerja terhadap kinerja karyawan. Simpulan yang dapat diambil adalah variable bebas dapat digunakan sebagai prediktor variable terikat. Artinya semakin besar gaji dan semakin lama masa kerja maka kinerja karyawan akan semakin baik. 


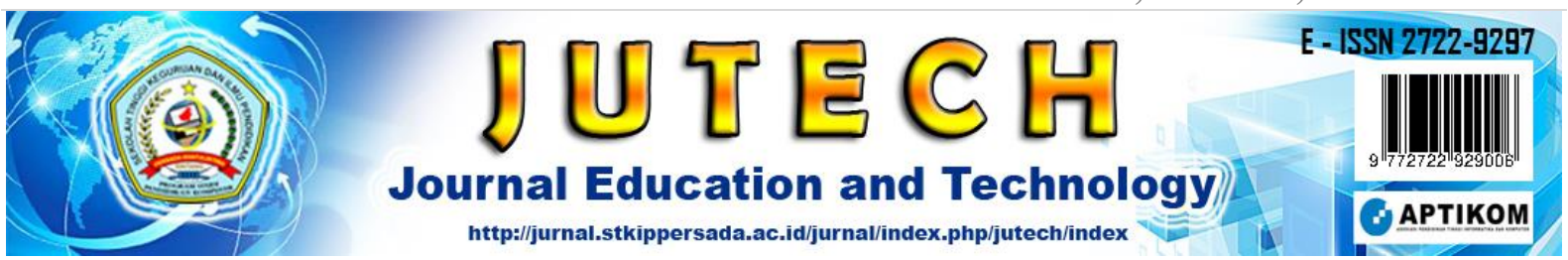

\section{PENDAHULUAN}

Trend perkembangan ilmu pengetahuan dan teknologi saat ini adalah revolusi industri 4.0. Integrasi teknologi digital berbasis cyber physical system pada hampir semua bidang pekerjaan menjadi ciri hadirnya revolusi industri tersebut (Schwab, 2016). Teknologi ini memungkinkan terhubungnya manusia dengan manusia, manusia dengan mesin, dan mesin dengan mesin (Devi et al., 2020; Xu et al., 2018). Perubahan karakteristik pekerjaan menjadi dampak tersendiri dari hadirnya revolusi industri 4.0 (Shahroom \& Hussin, 2018). Karakteristik pekerjaan yang berubah akan mendisrupsi pekerjaan yang telah ada dan menggantikanya dengan pekerjaan dengan karakteristik baru (Kergroach, 2017). Karakteristik baru pada pekerjaan juga membutuhkan kompetensi baru pada para pekerja (Manda \& Dhaou, 2019; Sharma, 2019). Dengan demikian, sangat penting bagi suatu negara untuk mengembangkan kompetensi berbasis industri 4.0 pada sumber daya manusianya. Sekarang ini, dalam dunia bisnis, setiap perusahaan harus bersiap untuk saling bersaing. Manajemen yang efektif dan keunggulan perlu dimiliki oleh setiap perusahaan untuk menyambut persaingan itu. Dalam hal ini, salah satu aspek yang berpengaruh besar terhadap kemajuan dan keberhasilan sebuah perusahaan adalah kinerja dari karyawannya. Faktor yang berpengaruh secara internal dapat terlihat dari penentuan gaji yang tepat oleh sebuah perusahaan kepada karyawan. Di samping itu juga perusahaan juga harus mau mengeluarkan bonus bagi para karyawannya yang berhasil bekerja maksimal sesuai yang dibutuhkan oleh perusahaan. Sementara itu, faktor yang berpengaruh secara eksternal dapat terlihat dari bagaimana sebuah perusahaan mampu memberikan pengembangan dan pelatihan pada para karyawannya. Dalam hal ini, perusahaan tidak dapat dipisahkan dengan tenaga kerja. Sekalipun perusahaan mempunyai teknologi canggih dan modal besar. Dengan tidak terdapatnya tenaga manusia sebagai penggerak, perusahaan tidak akan mampu meraih tujuan yang direncanakan. Oleh karenanya, diharapkan sumber daya manusia dapat mengalami peningkatan tahun demi tahun, seiring dengan berkembangnya teknologi dan majunya zaman. Salah satu masalah yang dihadapi adalah bagaimana mengetahui gaji yang akan dikeluarkan berdasarkan lama bekerja. Dalam penelitian ini, usulan penggunaan metodenya adalah dengan menggunakan perhitungan regresi sederhana. Pemilihan metode ini bertujuan agar nilai variabel terikat dapat diketahui dengan cara melakukan perhitungan pengaruh dari beberapa variable bebas. Pengembangan sistem ini, harapannya memberikan bantuan dalam memberikan prediksi kisaran gaji yang akan ditentukan berdasarkan berapa lama karyawan tersebut bekerja. 


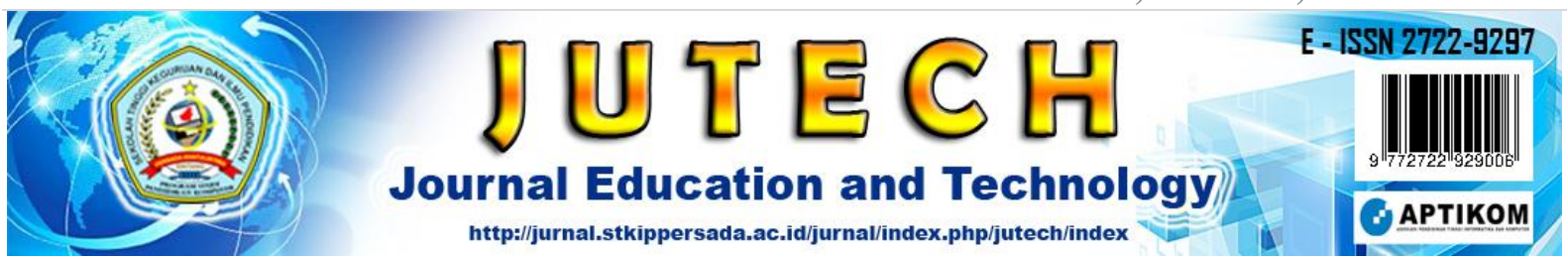

\section{METODE PENELITIAN}

Penelitian ini merupakan jenis penelitian deskriptif kualitatif yang menggunakan regresi linear sederhana dengan menggunakan Bahasa Python. Penelitian deskriptif adalah penelitian yang memberikan atau menggambarkan suatu keadaan atau fenomena yang ada dengan menggunakan proses ilmiah untuk menjawab permasalahan dunia nyata. Analisis data dilakukan secara kualitatif, termasuk mencari permasalahan yang lebih mendalam tentang suatu fenomena, fakta, atau peristiwa. Fakta, masalah, gejala dan peristiwa hanya dapat dipahami oleh peneliti bila diamati dan tidak dibatasi oleh ide-ide yang dangkal. Oleh karena itu, peneliti deskriptif kualitatif sering digunakan untuk menganalisis peristiwa, fenomena, atau situasi sosial.

\section{Pemograman Phyton}

Python merupakan bahasa pemrograman interpretatif multiguna yang menggunakan filosofi rancangannya berfokus pada tingkat keterbacaan kode. Sebagai bahasa pemrograman, Python menggabungkan kemampuan, kapabilitas dan sintaksis kode serta fungsi pustaka yang bermutu tinggi (Asadi, 2015). Secara umum, bahasa pemrograman hasil rancangan dari Guido van Rossum ini sesungguhnya sangat banyak dipakai oleh masyarakat umum dalam pembuatan program. Misalnya, aplikasi smartphone, program CLI, program GUI (desktop), game, web, IoT, program untuk hacking dan sebagainya (A Python Book: Beginning Python, Advanced Python, and Python Exercises. web.archive.org). Aplikasi kasir adalah program kasir, fungsiny adalah sebagai alat bantu dalam proses transaksi penjualan bisnis. Fungsi pokok aplikasi kasi, yang merupakan bentuk penggantian posisi mesin kasir konvensional, adalah membantu proses transaksi seperti pembayaran secara integratif. Aplikasi ini meggunakan metode Modular programming dimana Modular programming adalah teknik pemrograman dengan memisahkan kode menjadi beberapa bagian yang disebut dengan modules. Tujuannya untuk mengurangi ketergantungan antar modul. Teknik ini biasanya digunakan untuk software berskala besar. Software ini memiliki banyak modul di built sendiri-sendiri yang kemudian digabungkan untuk menjalankan fungsionalitas software tersebut. Dalam bahasa python, modul diimplementasikan dalam file berekstensi .py yang berisi sekumpulan kode untuk menjalankan task tertentu. Modul dapat berisi class, function, statement, atau kode-kode yang lain. Salah satu keuntungan penggunaan modul adalah reusable. Artinya modul ini dapat dipanggil oleh modul lain yang berbedabeda.

\section{Regresi Linear}

Regresi linear (linear regression) adalah metode yang dipakai untuk memperoleh model hubungan antara variabel dependen dan variabel independent (Walpole et al., 2012). Terdapat 2 jenis regresi linear yaitu, regresi linear sederhana (simple linear regression) dan regresi linear ganda (multiple linear 


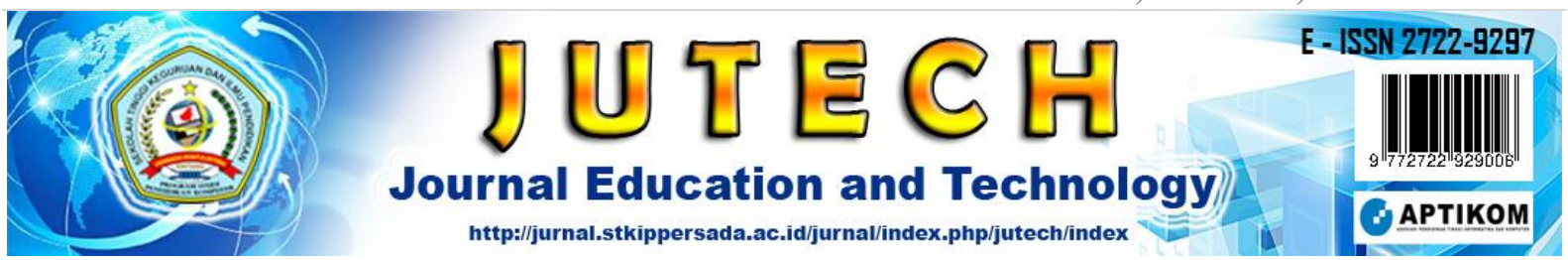

regression). Perbedaan terdapat pada banyaknya variabel independen. Regresi linear sederhana adalah metode yang dipakai untuk mendapatkan model hubungan antara satu variabel dependen dan satu variabel independen, sedangkan regresi linear ganda metode yang digunakan untuk memperoleh model hubungan antara satu variabel dependen dengan lebih dari satu variabel independen (Walpole et al., 2012). Penganalisisan regresi sederhana adalah hubungan antara variabel berjumlah dua, khususnya independent variable (variabel bebas), dan dependent variable (variabel tak bebas), sementara regresi dobel atau berganda adalah hubungan antara setidaknya tiga variabel, khususnya sekitar dua variabel bebas dengan satu variabel tak bebas.

a) Regresi Linier Sederhana

Penganalisisan regresi sederhana dipakai dalam menumbuhkan suatu persamaan yang menampilkan bagaimana hubungan antara variabel bebas (independen) dan variabel terikat (dependen), dan untuk mengantisipasi nilai variabel terikat jika nilai variabel bebasnya bertambah atau berkurang. Persamaan yang memaparkan bagaimana hubungan antara faktor $\mathrm{X}$ dan variabel $Y$ dan model kesalahan dikenal sebagai model regresi. Model regresi yang dipakai dalam regresi linear sederhana adalah:

$: \mathrm{Y}=$

dengan:

b0 dan b1 = parameter model

$\mathrm{X}=$ variabel independen

$\mathrm{a}=$ parameter intercept

$\mathrm{b}=$ parameter koefisien regresi variabel bebas

b) Scikit-learn

Scikit-learn merupakan modul Python yang menyediakan pelbagai jenis algoritma machine learning. Bentuk library python merupakan bentuk yang tersedia dalam Scikit-learn. Scikitlearn memanfaatkan task-oriented interface yang konsisten sehingga memudahkan dalam membandingkan antarmetode (Pedregosa, et al., 2011). Dengan prediksi gaji terhadap lamanya bekerja dapat dilakukan dengan model regresi linear sederhana, dimana makna dari regresi sendiri adalah alat estimasi yang dipakai untuk melakukan pengukuran ada atau tidaknya keterkaitan antarvariabel. Dalam penganalisisan regresi, kondisi regresi atau kondisi penilai dibentuk untuk memperjelas contoh keterkaitan variabel apakah ada beneran keterkaitannya satu sama lain. Keterkaitan yang diperoleh secara umum mengungkapkan hubungan praktis antara veriabel-variabel yang dimaksud. 'Regresi' sendiri kali pertama dipopulerkan oleh seorang pakar yang namanya adalah Fancis Galton pada tahun 1886. Menurut Galton (F. 


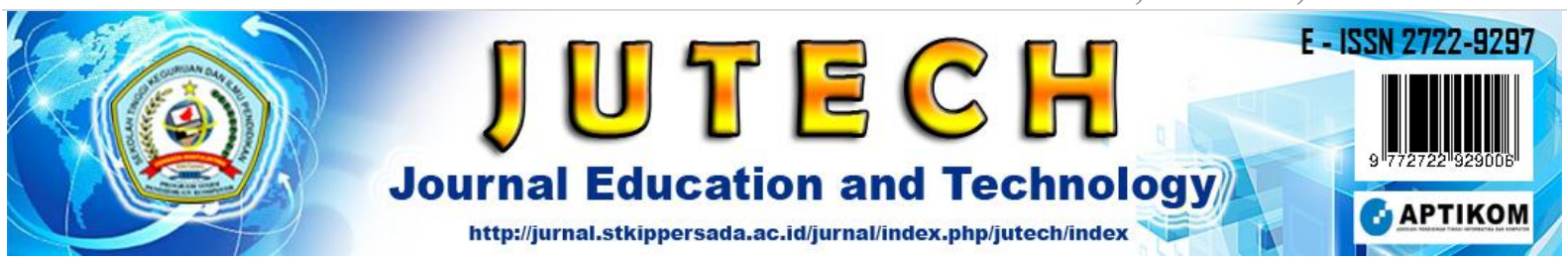

Galton, 1886), analisis regresi berkaitan dengan studi ketergantungan dari suatu variabel yang disebut variabel tak bebas (dependent variable), pada satu atau variabel yang menjelaskan dengan tujuan untuk memprediksi ataupun meramal nilai akhir dari variabel tak bebas apabila sudah diketahui nilai variabel yang menjelaskannya. Variabel yang menerangkan sering disebut variabel bebas (independent variable). Untuk mempelajari hubunganhubungan antara beberapa variabel, analisis regresi dapat dilihat dari dua bentuk yaitu: (1). Analisis Regresi Sederhana (Simple Regression) (2). Analisis Regresi Berganda (Multiple Regression).

\section{HASIL DAN PEMBAHASAN}

Dataset yang digunakan dalam hal ini adalah pengaruh gaji seseorang karyawan terhadap waktu kerja karyawan di perusahaan. Kumpulan data diambil, diurutkan dan dikonversikan ke angka dan Bahasa Indonesia untuk memudahkan dalam melakukan analisis terhadap pengaruh gaji karyawan. (Jogiyanto, 1999:129), mendefinisikan analisis sistem merupakan proses mengurai dari suatu sistem informasi yang utuh ke dalam bagian-bagian elemennya bertujuan untuk melakukan pengidentifikasian dan evaluasi masalahan-masalah yang terjadi, kesempatan-kesempatan, hambatan-hambatan dan keperluan-keperluan yang diuinginkan sehingga dapat dijadikan sebagai usulan untuk memperbaiki. Mulyadi (2001:377) mengemukakan, "gaji merupakan pembayaran atas penyerahan jasa yang dilakukan oleh karyawan baik yang mempunyai jabatan maupun karyawan pelaksana". Seorang karyawan menghasilkan gaji berupa:

1. Gaji Pokok

Ukuran pemberian gaji kepada pekerja adalah sesuai dengan posisi dan administrasi yang diberikan kepada organisasi dan kompensasi dasar telah diselesaikan ketika pekerja melakukan pekerjaan pertama kali.

2. Insentif

a. Uang makan dan transportasi

Merupakan ekspansi biaya seorang pekerja di samping gaji pokok dan ditentukan tergantung pada level dan posisi sesuai keahliannya dengan menghitungnya setiap hari tetapi diberikan kepada masing-masing saat gaiji dibayarkan.

b. Uang lembur

Menurut KEPMEN Pasal 1 Ayat 1 (2004:1), "waktu kerja lembur adalah waktu kerja yang melebihi 7 (tujuh) jam sehari dan 40 (empat puluh) jam 1 (satu) minggu untuk 6 (enam) hari kerja dalam 1 (satu) minggu atau 8 (delapan) jam sehari dan 40 (empat puluh) jam 1 


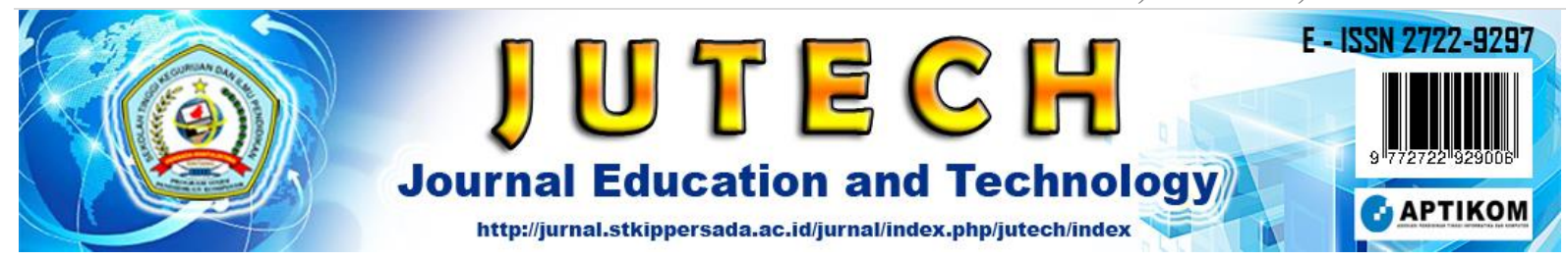

(satu) minggu untuk 5 (lima) hari kerja dalam 1 (satu) minggu atau waktu kerja pada hari istirahat mingguan dan atau pada hari libur resmi yang ditetapkan."

Tabel 1. Pengalaman Kerja Karyawan

\begin{tabular}{cc}
\hline Tahun_bekerja & Gaji \\
\hline 1.1 & 39343 \\
1.3 & 46205 \\
1.5 & 37731 \\
2 & 43525 \\
2.2 & 39891 \\
2.9 & 56642 \\
3 & 60150 \\
3.2 & 54445 \\
3.2 & 64445 \\
3.7 & 57189 \\
3.9 & 63218 \\
4 & 55794 \\
4 & 56957 \\
4.1 & 57081 \\
4.5 & 61111 \\
4.9 & 67938 \\
5.1 & 66029 \\
5.3 & 83088 \\
5.9 & 81363 \\
6 & 93940 \\
6.8 & 91738 \\
7.1 & 98273 \\
7.9 & 101302 \\
8.2 & 113812 \\
8.7 & 109431 \\
9 & 105582 \\
9.5 & 116969 \\
9.6 & 112635 \\
10.3 & 122391 \\
10.5 & 121872 \\
\hline & \\
\hline
\end{tabular}

Pengalaman kerja karyawan yang dikumpulkan merupakan tahun bekerja dan gaji. Tahun bekerja yang diperoleh merupakan wawancara hasil perkiraan tahun bekerja dimulai dari tahun pertama bekerja.

\section{Data Preprocessing}

Hasil dari pengumpulan data yang dilakukan akan didaftar ke dalam tabel. File berformat CSV merupakan data yang dipergunakan sebagai data training dalam melakukan penghitungan terhadap prediksi. File berformat csv tersebut di-save ke dalam folder dengan nama static dan dilabeli dengan Daftar_gaji.csv. Perubahan nilai data disesuaikan dengan mengacu tabel 1. 

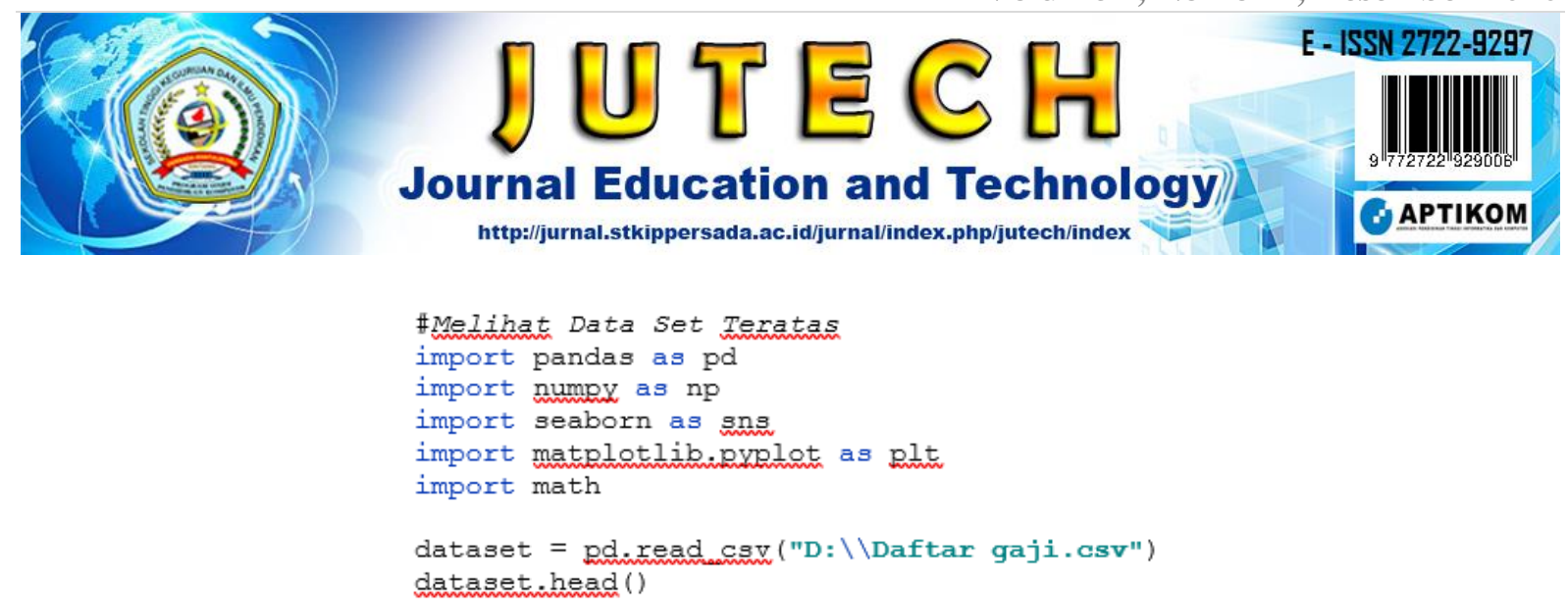

Gambar 1. Skript import dataset gaji karyawan pada Python

\begin{tabular}{crr} 
& Tahun_bekerja & Gaji \\
\hline count & 30,000000 & 30.0000000 \\
mean & 5.313333 & 76003,000000 \\
std & 2.837888 & 27414429785 \\
min & 1.100000 & 37731.000000 \\
$25 \%$ & 3200000 & 56720750000 \\
$50 \%$ & 47700000 & 65237.000000 \\
$75 \%$ & 77700000 & 1005447.750000 \\
max & 10.500000 & 122391.000000
\end{tabular}

Gambar 2. Hasil keluaran program

dataset.describe()berfungsi untuk melakukan analisis deskriptif secara otomatis terhadap dataset yang dipilih.

\section{Pengujian}

Pembahasan pengujian dalam penelitian yang dilakukan ini adalah melakukan perbandingan pengaruh variabel bebas terhadap variabel terikat dengan mengacu korelasi antara tiap-tiap variabel bebas (x) dan variabel terikat (y). Pengujian dengan melakukan pengukuran tingkat ketepatan pada model multiple linear regresson. Pengujian Model Linear regression. Untuk melakukan pengujian data secara menyeluruh, metode perhitungan akurasi sendiri akan diberlakukan. Penerapan metode melakukan perhitungan nilai total jumlah prediksi yang benar pada data memanfaatkan multiple linear regression. Untuk menetapkan koefisien-koefisien regresi ( ) dapat diketahui dengan memakai kode berikut: 

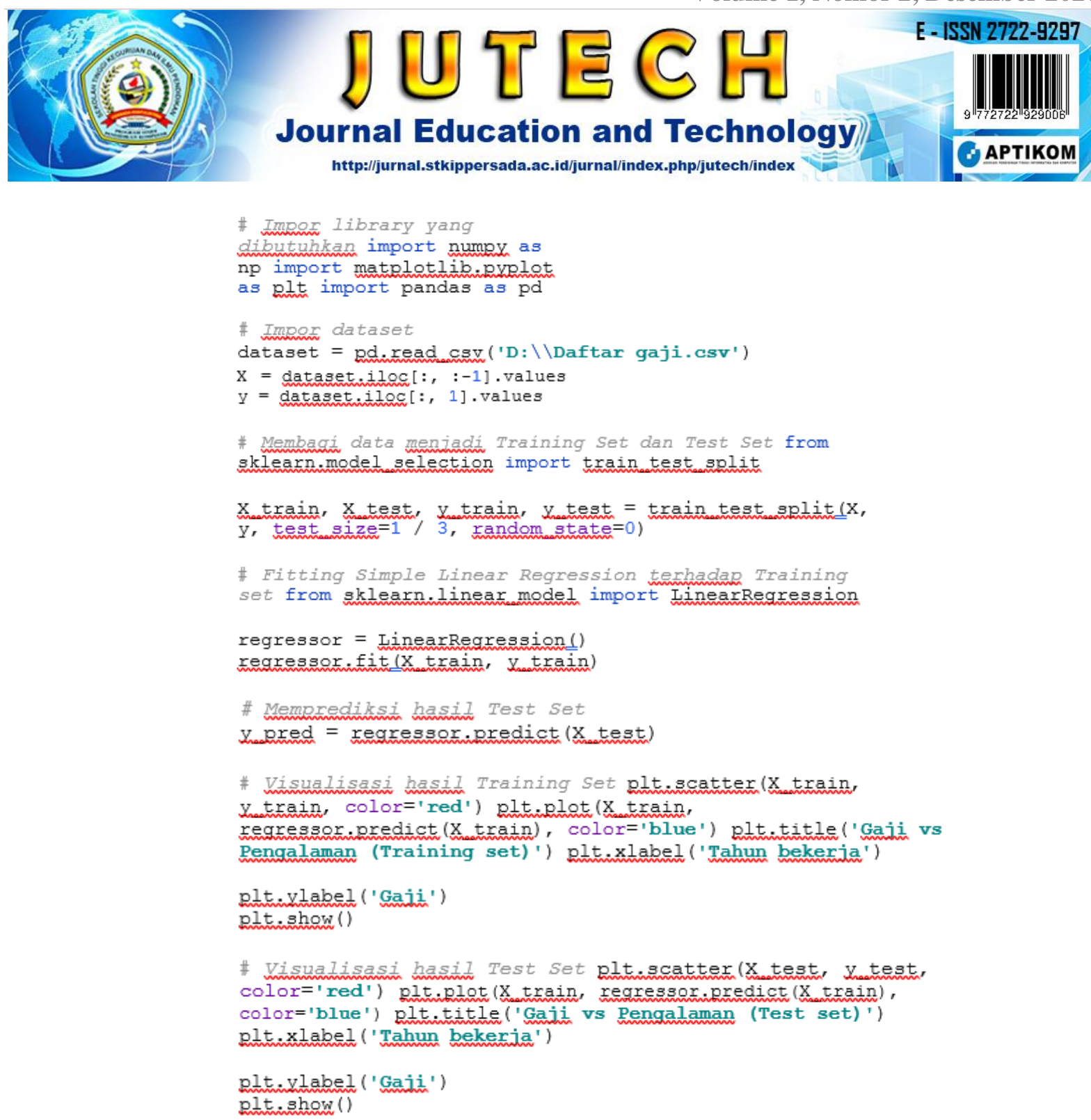

Gambar 3. Skrip pengujian model regresi linear

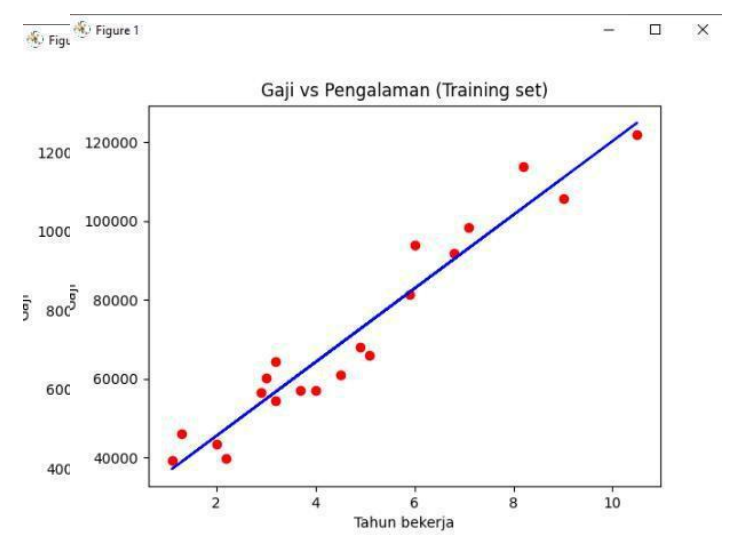

Gambar 4. Grafik prediksi gaji berdasarkan lamanya bekerja

Keterangan:

- Line 2 hingga 4 adalah mengimport library yang dibutuhkan. 


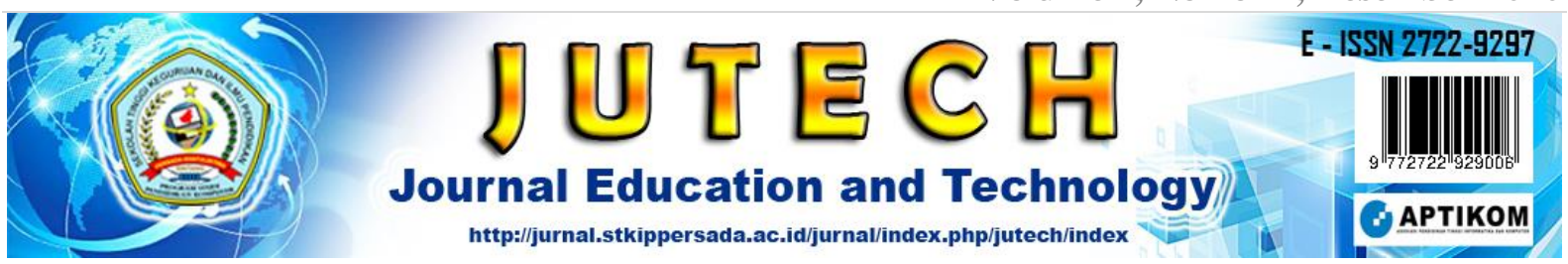

- Line 7 mengimport data ke python.

- Line 8 menetapkan variabel independent (sumbu x) yakni kolom pertama/1 (Tahun_bekerja). Perlu diberikan perhatian, saat melakukan slicing memakai method .values, hal ini hanya akan memotong data tanpa headernya. Jika tanpa .values maka header dari slicing akan diturutsertakan.

- Line 9 menetapkan variabel dependen (xumbu y) yakniikolom kei2 (Gaji).

- Line 12 mengimport library untukimemisahkan menjadi train set dan test.

- Line 13 memisahkan menjadi train set dan test, dengan train setnya adalah $2 / 3$ dariidataset yang ada. Andaibisa mengklik bagian Variableiexplorer di spyderiuntuk mengetahui hasil bagi antara trainidan test setnya.

- Line 16 mengimport class LinearRegression dari library sklearn.linear_model yang dibutuhkan dalam pembuatan model regresi.

- Line 17 menciptakan objek regressor sebagai fungsi dari LinearRegression. Hanya dengan menuliskan LinearRegression(), model regresi sudah dipersiapkan. Jika Anda kursor diarahkan pada LinearRegression kemudian mengklik CTRL + i maka akan tampil object inspector untuk LinearRegression. Di tahap ini, Anda bisa mengetahui parameter apa saja yang dibutuhkan.

- Line 18 menciptakan model regresi untuk train set dengan menulis regressor.fit(X_train, y_train). Untuk mengetahui parameter apa saja yang dibutuhkan dalam metode fit(), hanya dengan mengarahkan kursor pada .fit() lalu mengklik CTRL+i.

- Line ke 18 adalah proses pembuatan model machine learning regresi. Berarti, dalam hal ini model tengah belajar untuk menemukan hubungan antara X_train dan y_train.

- Keluaran pada python akan terlihat sebagai berikut.

Out (12): Linear Regression (copy_X=True, fit_intercept $=$ True, $n \_j o b s=1$, normalize $=$ False). Setelah machine learning mempelajari mengetahui hubungan antara X_train dan y_train, maka tahapan berikutnya adalah melakukan percobaan dengan membuat prediksi ke depan. Prediksi ini memakai hubungan yang telah dipelajari oleh model. Perintah untuk melaksanakan prediksi ini dilakukan pada line 21.

- Line 21 memprediksi dengan memakai metode .predict. Dalam rangka mengetahui parameter apa saja, dapat dilakukan melalui object inspector. Parameter yang dibutuhkan adalah variabel independent, dalam hal ini adalah X_test dan bukan X_train. Kenapa seperti itu? Sebab ingin membuat prediksi data baru. Jika memakai X_train perlu membuat prediksi berdasarkan 


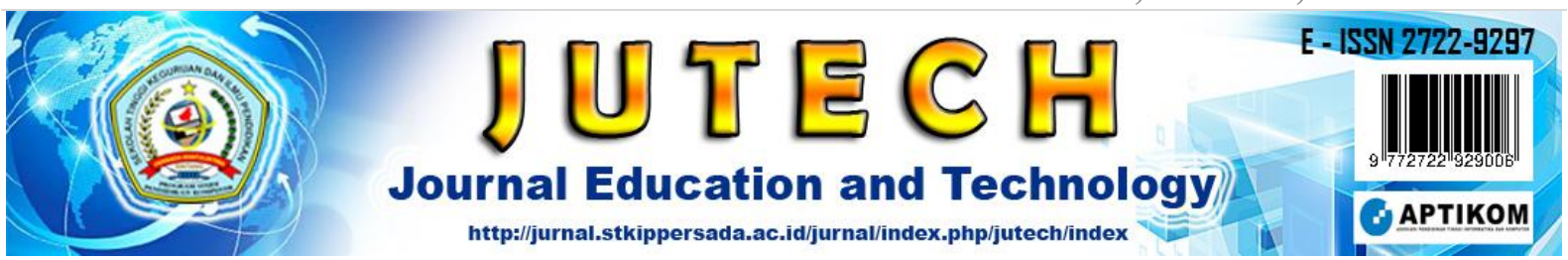

pemahaman X_train, sedangkan pemahaman itu sendiri dibuat mengacu X_train. Memakai X_test. Nanti, prediksi ini dibandingkan dengan y_test. Apabila hasil yang didapatkan mendekati (jarak tidak terlalu jauh), maka model dianggap baik.

Setelah itu, jika telah selesai dilakukan, berikut hasil tersebut bisa dibandingkan antara hasil y_pred dan y_test, dengan y_pred merupakan prediksi model dan y_test merupakan data sebenarnya.

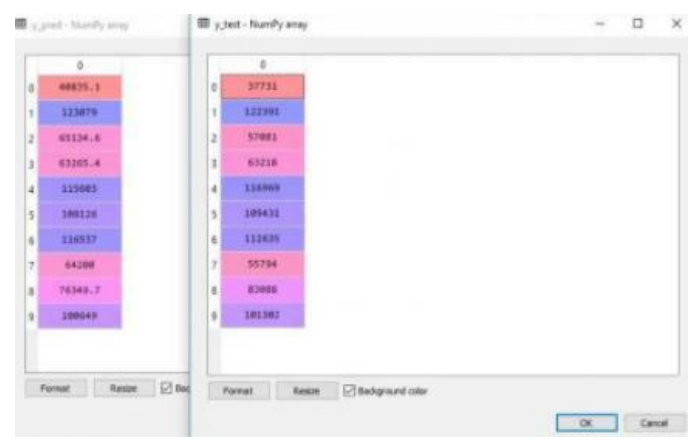

Gambar 5. Hasil y_pred dan y_test

Agar dapat melakukan perbandingan hasil antara y_pred dan y_test, hasilnya sangat baik apabila dilakukan pembuatan berupa ilustrasi visual. Hal yang harus diperhatikan, supaya penampilan visualnya baik di python, maka block semua line dari line 24 hingga line 29 lalu mengklik CTRL + ENTER.

- Line 24 membuat scatter plot X_train dan y_train dengan warna merah untuk data poinnya. Tentu saja warnanya bisa diubah sesuka hati.

- Line 25 membuat line plotnya (garis regresi) berwarna biru. Metode plot() memerlukan parameter pertama, yakni data poin untuk sumbu x, dan parameter kedua merupakan data poin untuk sumbu y. Data poin sumbu x adalah X_train sebab hendak melihat model regresi dari training set, sedangkan data poin sumbu y merupakan prediksi dari X_train dengan perintah regressor.predict(X_train). Harus diperhatikan, data poin sumbu y bukan y_predict atau regressor.predict(X_test), sebab, kali ini bertujuan membuat plot regresi untuk X_train, bukan X_test. Misalnya, Anda melakukan kesalahan, memakai regressor.predict(X_test), maka garis regresinya tidak akan muncul. Kenaapa? Sebab, jumlah data poin X_train (20 baris) dan X_test (10 baris) sudah memiliki perbedaan, maka tidak mungkin bisa dibuat garis regresinya.

- Line 26 membuat judul yang akan tampil pada bagian teratas grafik.

- Line 27 membuat label untuk sumbu x.

- Line 28 membuat label untuk sumbu y.

- Line 29 melakukan eksekusi dan menampilkan hasil dari semua perintah dari Line 24 hingga Line 28. 

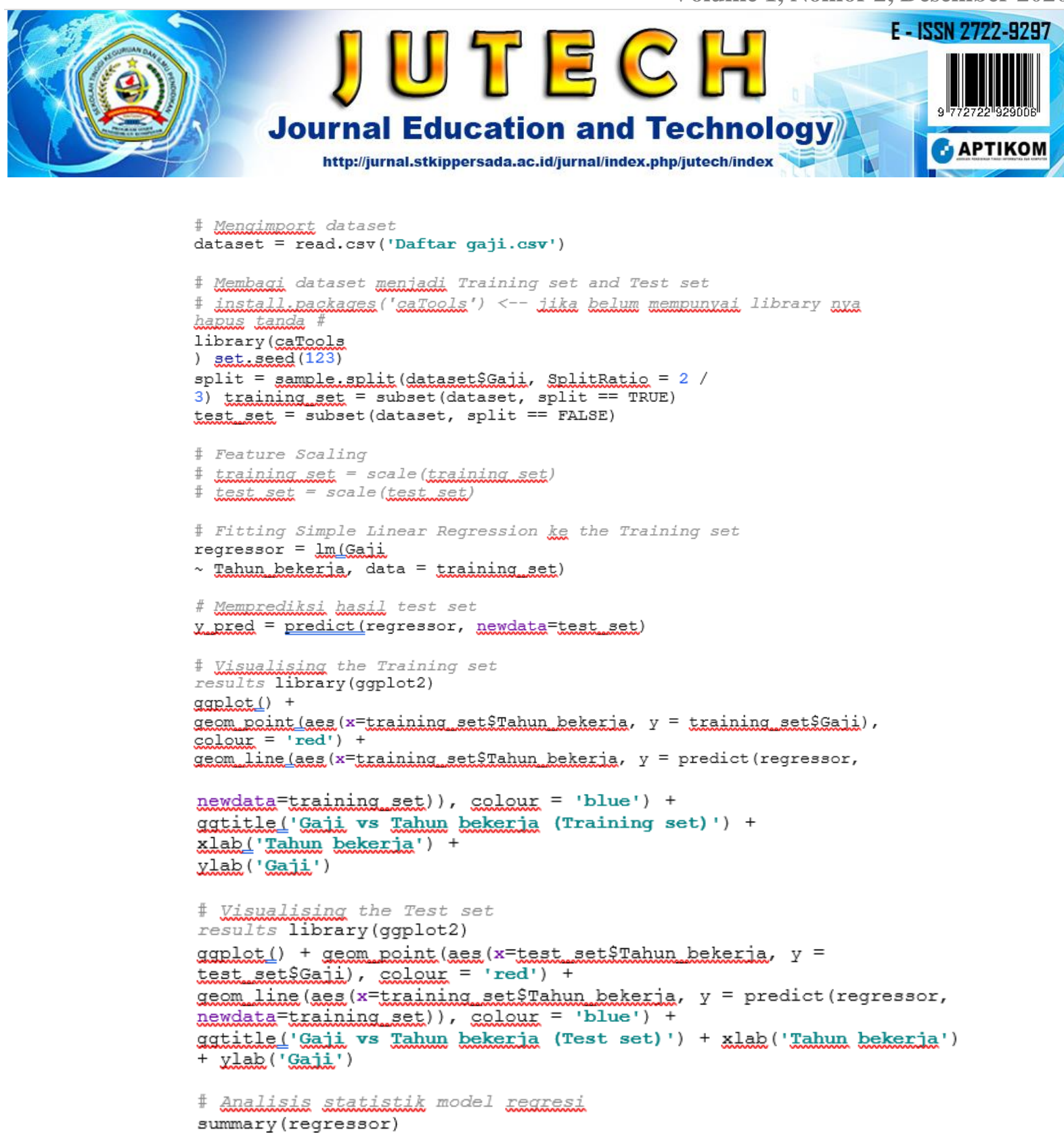

Gambar 6. Skrip analisis static model regresi

Keterangan:

- Line 2 mengimport dataset.

- Line 6 mengimport libraryicaTools untuk melakukan pembagian data keitest set danitrain.

- Line 7 menetapkan bilanganirandom (contohnya kali ini bilangan 123 . Tentu saja angkanya bebas).

- Line 8 memberikan definisi variabelisplit untuk membagi test set dan train. Agar dapatimelihat parameter apa sajaoyang dibutuhkan, kursor hanya harus diarahkan pada sample.split, lalu mengklikoF1. Setelah itu memmunculkan dokumentasi. Parameter pertama adalah variabel dependen (Salary), lalu rasio split secara default sebesar 2/3.

- Line 9 menetapkan bagian trainingiset, dariihasil Boolean TRUE dari variabelisplit. 


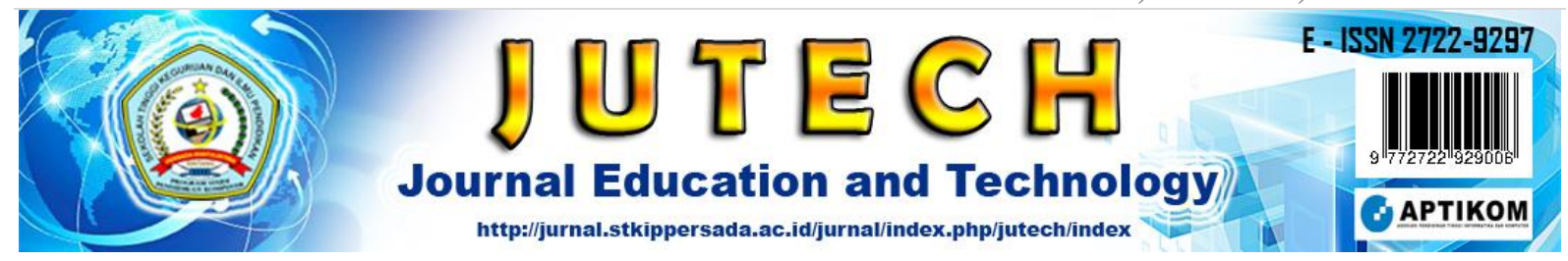

- Line 10 menetapkan bagian testiset, dariihasil booleaniFALSE dari variabelisplit.

- Line 12 hingga Line 14 merupakan perintah featureiscaling jika dibutuhkan. Namun, kaliiini tidak membutuhkannya.

- Line 17 memberikan definisiiobjek regressorisebagai suatu modeliregresi. DiiR, perintah membuat modeliregresi adalah dengan memakaiofungsi $\operatorname{lm}()$. Parameteropertama adalah variabel dependent (Gaji) diikuti denganosimbol (disebutotilde). Lalu, setelahosimbol diikuti denganovariabel independentoyaitu Tahun_bekerja, dan definisikan data diambilodari training_set.

- Line 20 merupakan prediksiipembelajaran machineilearning untuk testiset. Line 20 ini sama dengan Line 21 y_pred dalamiperintah bahasaipython yang telah disebutkan.

- Line 23 mengimport library ggplot2 untukomembuat visualisasi modeli regresi. ggplot2 adalah library yang terkenalodi R, sebab dapat menampilkanovisual yangoberagam dan powerful. Harus diberikan perhatian, sebenarnya ggplot ditulis dalam satuibaris, tetapiiAnda melanjutkan melanjutkan penulisan diobawahnya jika layar komputer yang digunakanotidak dapat menampilkanosemua perintahodalam satuobaris. Apabila mengklikoENTER, maka otomatis akanidialihkan ke baris diibawahnya, danoR otomatisijuga akan memberikan identitas (sedikit menjorok kanan).

- Line 24 perintah awaliggplot, dituruti denganiparameter berikutnyaidengan simbol + (plus). Perintah ggplot() adalah menyiapkan objekovisualisasi, yang apabila dituruti simbol + , maka seluruh komponenivisualisasi setelahisimbol + akanidieksekusi bersama.

- Line 25 membuat scatteriplot denganiperintah geom_point dituruti denganoaes (penyingkatan dari aesthetic) untuk menetapkan manaisumbu x danimana sumbuiy, dan warnaiapa yang diinginkan.

- Line 26 membuat plotiline denganiperintah geom_line. Parameter samaidengan geom_point.

- Line 27 memberi judul untuk grafik

- Line 28 memberi label untuk sumbu $\mathrm{x}$

- Line 29 memberi label untuk sumbu y

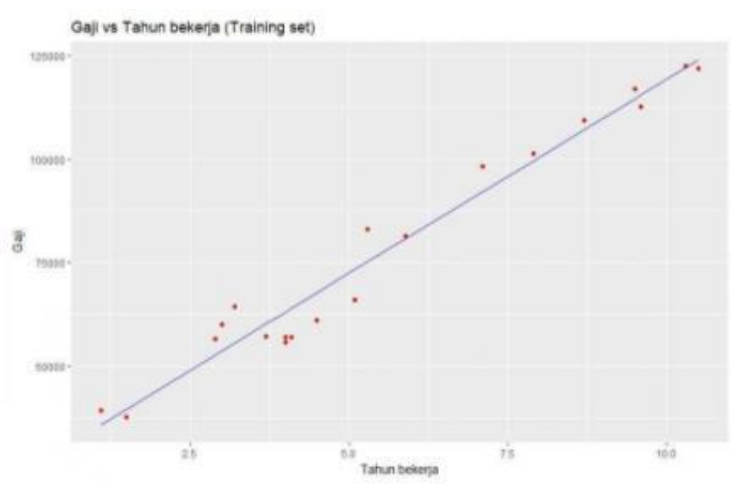

Gambar 7. Hasil Regresi Training Set 


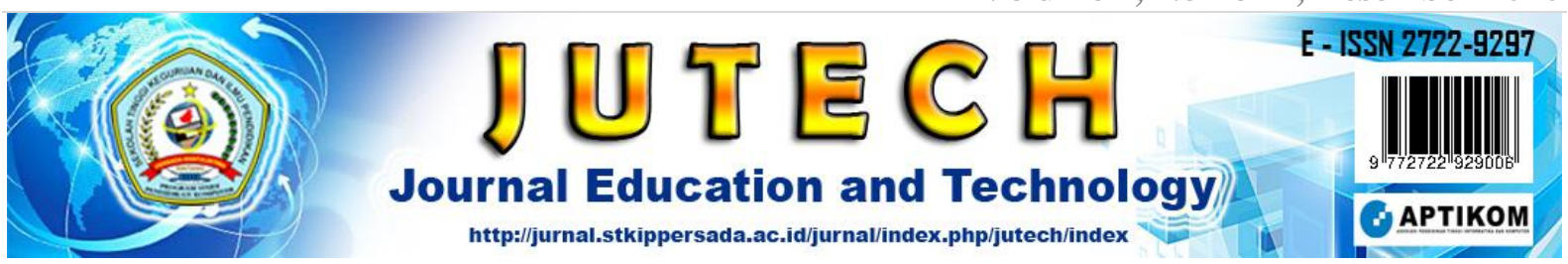

- Line 32 hingga Line 38 menanjukkan grafik test set.

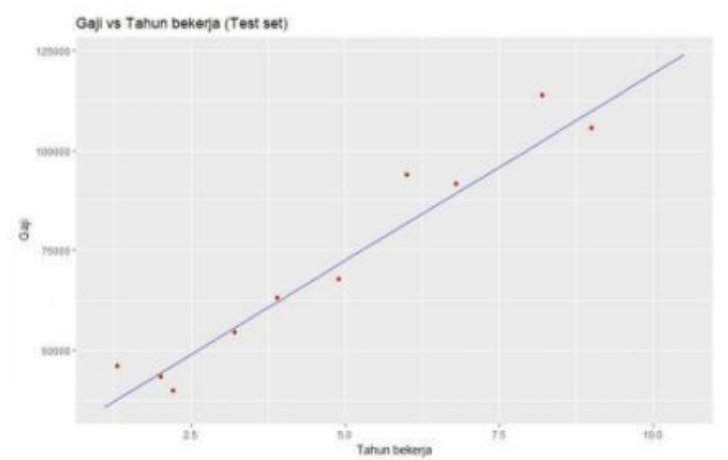

Gambar 8. Hasil Regresi Test Set

Agar dapat menjamin keakuratannya, hal yang diperlukan adalah pengujian statistik. Maksudnya adalah, $\mathrm{R}$ memang dibuat sebagai software statistik, sehingga pengujiannya hanya dengan menuliskan perintah summary pada line 41 .

- Line 41 perintah mengetahui seberapa baik (fit) model regresi yang dibuat. Hanya dengan menuliskan summary (kemudian mengikut model regresi)

Eksekusi dari model regresi, yakni :

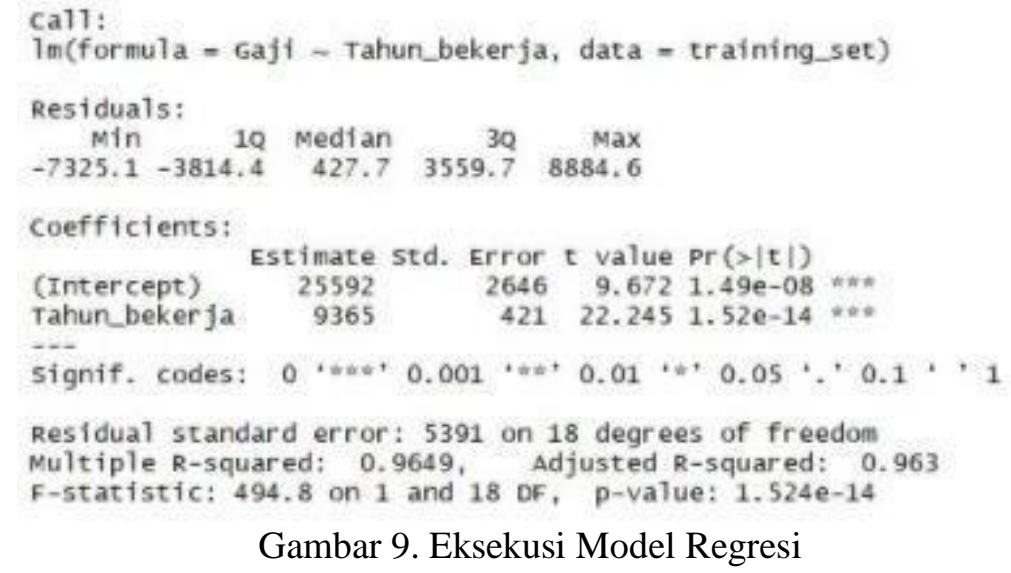

Residual merupakan banyaknya data poin yang tidak dapat diberikan penjelasan dengan model. Gambarannya secara umum, makin kecil residual, makin kuatlah model regresi memberikan penjelasan hubungan antara variabel dependent dan independent. Min sebagai nilai minimal, 1Q nerupakan residual kuartal pertama (persentil 25), median merupakan nilai tengah, 3Q adalah persentil 75, dan Max merupakan nilai paling besar. Bagian Coefficients dijelaskan sebagai berikut:

- Intercept adalah koefisien dari sebuah model regresi. Dalam hal ini, berarti tiap nilai X nol (karyawan belum berpengelaman kerja), ia menerima gaji sebanyak 25592 tiap tahun. Angka ini dapaat dilihat pada bagian Estimate dari Intercept. 


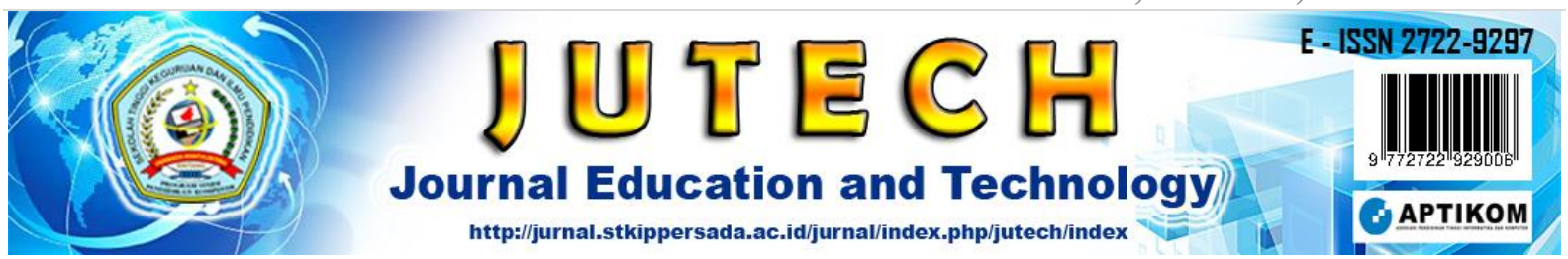

- Lalu, di bagian Tahun_bekerja nilai 9365 mengungkapkan bahwa tiap pertambahan satu tahun kerja, gaji yang diterima akan mengalami pertambahan sebanyak 9365 tiap tahun.

- Persamaan regresi dapat dituliskan dalam bentuk berikut:

$$
\text { Gaji }=25592+9365 * \text { Tahun Bekerja }
$$

- Std.Error (standar error) merupakan penyimpangan data prediksi dari data sebenarnya. Makin kecil std. error, tentu modelnya pun dianggap makin baik.

- $\quad t$ value merupakan pengujian statistik dari distribusi t. Nilai t di atas 2 atau kurang dari -2 umumnya diasumsikan signifikan.

- Pr adalah p value. Variabel independen (Tahun_bekerja) mempunyai nilai p di bawah 0.05 , hal ini menandakan ia signifikan melakukan prediksi variabel dependen (Gaji).

- Apabila ingin mengetahui seberapa baik, lihatlah bagian Multiple R-squared yang merupakan nilai dengan besarnya kisaran 0 hingga 1. Nilai nol (0), berarti error (jarak antara nilai prediksi dan nilai sesungguhnya) terlalu besar, sehingga model yang dipakai dianggap sangat buruk. Sebaliknya, apabila $\square$ nilainya 1 , modelnya dianggap sempurna, berarti prediksi yang diberikan dianggap akurat tanpa error sedikit pun.

Hal yang pasti, model regresi tidak mungkin mempunyai nilai 1 . Sebab, apabila seperti yang disebutkan, modelnya diartikan terlalu sempurna. Model mempunyai nilai 0.96 tentu, modelnya sangat baik. Apabila melakukan pendekatan regresi, lalu nilainya sangatlah buruk, misalnya di bawah 0.5 atau bahkan dekat dengan angka nol, hal ini dapat dijamin keterkaitan antara variabel dependen dan independen tidaklah linear. Apabila benar seperti yang telah disebutkan, hal yang harus dilakukan adalah dengan fitting (melihat hubungan variabel dependen dengan independen) dengan model regresi polinomial, atau nonlinear.

\section{SIMPULAN}

Berdasarkan pengujian menggunakan fungsi linear regression untuk memprediksi besarnya gaji (Y) dari pengalaman bekerja (X) diketahui bahwa semakin bertambahnya pengalaman bekerja seorang karyawan maka gaji karyawan tersebut juga akan bertambah setiap tahunnya. Hasil tersebut menunjukan bahwa pengalaman bekerja memberikan pengaruh positif terhadap besarnya gaji karyawan. Hasil tersebut disimpulkan bahwa semakin lama pengalaman bekerja seorang karyawan maka semakin berpengaruh positif terhadap gaji yang akan diterima. Sehingga fungsi linear regression layak digunakan untuk memprediksi pengaruh pengalaman kerja terhadap gaji karyawan. 


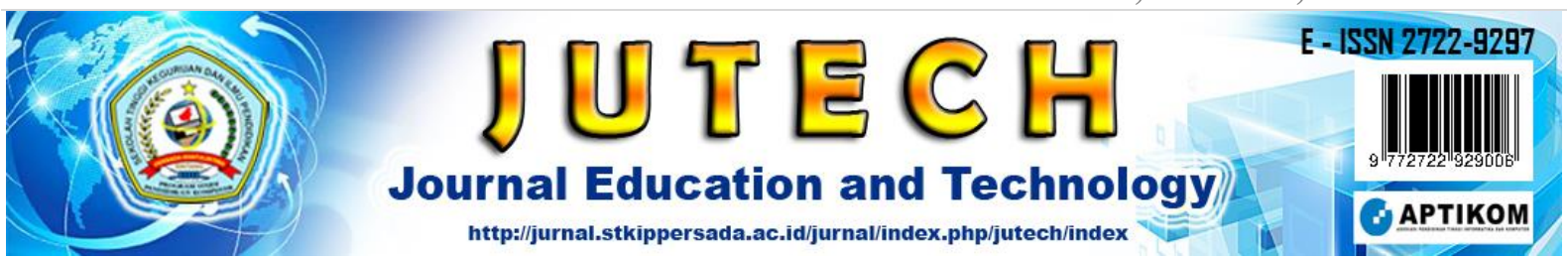

\section{DAFTAR RUJUKAN}

Asadi, A. (2015). The Pyhon Book. In Imagine Publishing Ltd.

Devi, M., Annamalai, M. A. R., \& Veeramuthu, S. P. (2020). Literature education and industrial revolution 4.0. Universal Journal of Educational Research, 8(3), 1027-1036. https://doi.org/10.13189/ujer.2020.080337

F. Galton. (1886). Regression Towards Mediocrity in Hereditary Stature. The Journal of the Anthropological Institute of Great Britain and Ireland, Vol. 15, 246-263. https://doi.org/10.2307/2841583

F. Pedregosa, G. Varouquaux, A. Gramfort, V. Michael, B. Thirion, O. Grisel, M. Blondel, P. Prettenhofer, R. Weiss, V. Dubourg, J. Vanderplas, A. Passos, D. Cornapeau, M. Brucher dan M. P, A. (2011). Scikit-learn: Machine Learning in Python. Journal of Machine Learning Research 12, 2825-2830. https://doi.org/10.1289/EHP4713

Jogiyanto, H. (1999). Analisis \& Desain Sistem Informasi (2nd ed.). CV ANDI OFFSET.

Kergroach, S. (2017). Industry 4.0: New challenges and opportunities for the labour market. Foresight and STI Governance, 11(4). https://doi.org/10.17323/2500-2597.2017.4.6.8

Manda, M. I., \& Dhaou, S. Ben. (2019). Responding to the challenges and opportunities in the 4th industrial revolution in developing countries. ACM International Conference Proceeding Series, Part F1481. https://doi.org/10.1145/3326365.3326398

Mulyadi. (2001). Sistem Akuntansi. In Edisi 3. Salemba Empat.

Schwab, K. (2016). The Fourth Industrial Revolution. World Economic Forum.

Shahroom, A. A., \& Hussin, N. (2018). Industrial Revolution 4.0 and Education. International Journal of Academic Research in Business and Social Sciences. https://doi.org/10.6007/ijarbss/v8-i9/4593

Sharma, P. (2019). Digital Revolution of Education 4.0. International Journal of Engineering and Advanced Technology, 9(2), 3558-3564. https://doi.org/10.35940/ijeat.a1293.129219

Walpole, E. R., Myers, H. R., Myers, L. S., \& Ye, K. (2012). Probability and Statistics For Engineers and Scientists. Mass: Pearson Education.

Xu, M., David, J. M., \& Kim, S. H. (2018). The fourth industrial revolution: Opportunities and challenges. International Journal of Financial Research, 9(2). https://doi.org/10.5430/ijfr.v9n2p90 